\title{
Risk of mesothelioma from exposure to crocidolite asbestos: a 1995 update of a South African mortality study
}

\author{
Danuta Kielkowski, Gillian Nelson, David Rees
}

\begin{abstract}
Objective-To find the risk of developing mesothelioma in a cohort born in 1916-36 in Prieska, Northern Cape Province, South Africa.

Methods-A birth cohort mortality study was carried out in a small town in the Northern Cape Province, South Africa, with a history of crocidolite asbestos mining and milling. The cohort comprised all white births registered in the magisterial district of Prieska from 1916 to 1936, inclusive (2390). Causes of death due to mesothelioma and other cancers as recorded on medical certificates of cause of death were investigated. Person-years analysis was used to calculate mortalities due to mesothelioma, other respiratory cancers, and other non-respiratory cancers. Proportional cancer mortalities were also calculated for mesothelioma and other specific neoplasms.
\end{abstract}

Results-The follow up rate for the cohort was $74.3 \%$ in 1995 , and 683 traced members $(38.6 \%)$ had died. Cause of death was unknown for $6.4 \%$ of deaths. There were 118 cases of cancer, 28 of them from mesothelioma, giving a cause specific mortality for mesothelioma of 277 (170-384) per $10^{6}$ person-years. The rates for men and women were 366 and 172 per $10^{6}$ person-years, respectively. The mortality for lung cancer (29 deaths) was 287 (135-436) per $10^{6}$ person-years, and that for other non-respiratory cancers (60 deaths) was 593 (442-745). Two cases of laryngeal and four of colon cancer were observed. All cancer mortality, mesothelioma, and lung cancer proportional cancer mortality ratios were increased.

Conclusion-The mortality for mesothelioma in men was twice that in women, probably because men were more likely to have had both occupational and environmental exposure to asbestos. Nevertheless, the mortality in women was still high and is probably indicative of the environmental exposure as white women were rarely employed in the asbestos industry in the Prieska area. Due to the long latency from first exposure to diagnosis of the neoplasm, the cause specific mortality in this cohort could be expected to increase rapidly over the next 10 years. (Occup Environ Med 2000;57:563-567)

Keywords: South Africa; asbestos; environmental exposure; occupational exposure; cohort; mesothelioma; lung cancer
Prieska is a small, remote town in South Africa, close to a crocidolite asbestos mining area that was productive from 1893 to the late 1960s. Twenty four crocidolite rich deposits had been identified in the Prieska magisterial district by 1930. ${ }^{1}$ These were mined at various times from 1919-43 by the Cape Asbestos Company and from 1929 by smaller companies. A crushing mill was built in Prieska town in 1930, and residents were exposed to asbestos fibre emissions from the mill which was close to both the residential and business areas, ${ }^{2}$ until at least 1964. Local residents, however, remember the mill working in the late 1970 s. Other sources of exposure were the asbestos dumps (on which children played); spillage of fibres during transport; and tailings which were used for, among other things, surfacing roads and making bricks. ${ }^{3}$ The last major store of asbestos was removed from the town in 1982. Homes are still polluted through years of wind blown fibres accumulating in the ceilings.

Several studies have shown an increased risk of developing mesothelioma or respiratory cancer after occupational and environmental exposure to crocidolite. ${ }^{4-7}$

Botha et $a l^{6}$ reported an annual death rate due to asbestosis or mesothelioma for white people of 542 per million for a high exposure crocidolite area (which included Prieska), 87 for a low exposure crocidolite area, and 24 in a control area. By comparison the rates for the coloured (mixed race) population were 573 per million and 215 per million in the high and low exposure areas respectively. The standardised mortality ratio (SMR) was increased for all cancers in both population groups and sexes. This was significant except for white women. The lung cancer SMR was moderately increased at 1.73 for white men, 1.87 for white women, and 1.28 and 2.47 for coloured men and women respectively. Significance was reached for white men and coloured women. An interesting result was the increase in the SMRs for stomach cancer and neoplasms of the digestive organs and peritoneum for both men and coloured women.

Sluis-Cremer et al showed a mesothelioma rate of 446 per million person-years for white men employed in crocidolite mining. ${ }^{7}$

Cases of mesothelioma induced by environmental (non-workplace) asbestos exposure are well documented, with domestic exposure due to relatives working with asbestos a common source. ${ }^{8-11}$ A recently published study from Australia estimates the incidence of mesothelioma due to environmental asbestos exposure in Wittenoom as 270 per million person-years. ${ }^{12}$ 
Not surprisingly, an unusually large number of cases of mesothelioma among the residents of Prieska have been reported over the past few decades, which was the motivation for this study in which the risks of developing mesothelioma or other respiratory cancers were calculated for this community. Preliminary data were published in $1990^{5}$; this paper updates the findings to 1995.

\section{Methods}

SUBJECTS

This cohort mortality study included all white people whose births were registered in the magisterial district of Prieska in 1916-36. Subjects who were not white had to be excluded because of poor official records. The cohort was established by copying the birth register for the Prieska district for the selected years.

The unique national identity number and vital status of the 2390 cohort members was sought in the computerised population registry of the Department of Home Affairs. The registry contains the unique identification number, surname, all names, birth date, address, and if the person has died, the date of death and cause of death. This registry is organised by unique identification number but it can be searched also by surname and birth date. For each computerised record a physical file exists which contains original documents such as death registration and medical death certificates. Not all cohort members were entered into the computerised registry-namely, those who died before it was established in 1972, and those who had not obtained an identity document. In these cases, information was obtained by a manual search of the physical files.

The identity numbers were subsequently used to ascertain vital status throughout the follow up period. The identity numbers were periodically sent to the Department of Home Affairs, which provided copies of the medical certificate of death and the death register form of cohort members who had died.

If a person dies at the age of $\leqslant 10$, the name of one or both parents (or the guardian) is recorded on a form along with information such as place of birth and address, parents' names, and places of residence. These documents are completed when a person (usually a relative) informs a death registration officer about a death, and are bound in annual death registers according to the magisterial district where the death occurred. We manually searched the death registers of the Prieska magisterial district for deaths that occurred in cohort members during infancy or childhood. We examined the Prieska death registers (archived records) for the years of death 1917-46 (I936 plus 10 years). We were able to examine the birth registers from which the cohort was originally compiled to find whether the dead person belonged in the cohort.

Cohort members who were not entered into the Registry or who had left the area and died elsewhere (thus not entered into the Prieska death registers) are lost to follow up, unless they obtained identity numbers through the course of the study.

DATA ANALYSIS

All deaths among white people that had been detected by the end of 1995 are included in the analysis. Descriptive statistics include a comparison of number of deaths within different age groups for specific causes of death; cancers are of particular interest.

Person-years analysis was used to calculate mortalities due to mesothelioma and other respiratory cancers (lung and bronchus). Personyears were the number of years from birth to death for deceased cohort members and the years from birth to the end of 1995 for those still living. Proportional cancer mortality ratios (PCMRs) for mesothelioma and other respiratory cancers were also calculated, with the white South African population as comparison. ${ }^{13}$ Sex specific and total expected numbers were calculated from people who had died at $\geqslant 30$ so the age profile of the studied population and reference population were the same. The $95 \%$ confidence intervals $(95 \%$ CIs) for the specific mortalities and PCMR analysis were calculated from the Poisson distribution.

\section{Results}

In the period 1917-36 a total of 5898 births were registered in the Prieska district. Of these $2390(40.5 \%)$ were white, $2376(40.3 \%)$ were coloured, 909 (15.4\%) were black, and 16 $(0.3 \%)$ were Asian (table 1$)$. The population group of the remaining 207 births $(3.5 \%)$ was not stated in the registers.

By the end of 1995 a total of 2410 members of the cohort were traced (table 1), most of whom were white $(73.7 \%)$. Of the white people who were traced $38 \%$ had died. A disappointingly small proportion of cohort members who were not white could be traced, so analysis had to be restricted to white subjects.

As figure 1 shows, the age group with the highest proportion of deaths $(44.8 \%)$ was mature adults, followed by infants $(24.9 \%)$. The most common causes of death in infants, as stated on the death certificates, were complications of pregnancy, childbirth, and purpureum (33\%), followed by respiratory diseases such as pneumonia (17\%), and other infectious and parasitic diseases (15\%). All the deaths of children $<15$ years of age (257) were identified by manually searching the death registers for the Prieska district. This considerably improved the tracing of the cohort, from $65 \%$ to $74 \%$.

Table 1 Number of registered births, traced cohort members, and deaths (by population group)

\begin{tabular}{lllllll}
\hline & $\begin{array}{l}\text { Registered } \\
\text { births }\end{array}$ & \multicolumn{2}{c}{$\begin{array}{l}\text { Traced cohort } \\
\text { members }\end{array}$} & & \multicolumn{2}{c}{$\begin{array}{l}\text { Deaths in traced } \\
\text { cohort members }\end{array}$} \\
\cline { 3 - 4 } & $n$ & $n$ & $\%$ & & $n$ & $\%$ \\
\hline White & 2390 & 1776 & 74.3 & & 683 & 38.4 \\
Coloured & 2376 & 510 & 21.6 & & 367 & 72.1 \\
Black & 909 & 118 & 13.0 & & 111 & 94.1 \\
Asian & 16 & 3 & 18.8 & & 2 & 66.7 \\
Unknown & 207 & 3 & 0.0 & & 0 & - \\
Total & 5898 & 2410 & 40.9 & & 1163 & 48.2 \\
\hline
\end{tabular}



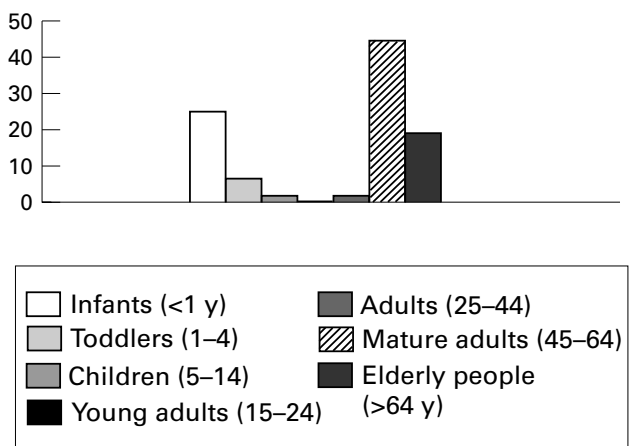

Figure 1 Percentage of deaths by age category in 683 white cohort members who had died by 1995.

By the end of 1995, $683(38.4 \%)$ of the traced cohort members had died, the cause of death was unknown for only $6.4 \%$ of deaths. There were 118 cancer deaths. Except for one case of sarcoma in an infant, these cancers occurred in subjects $>35$ years (fig 2 ). Twenty eight deaths from mesothelioma (one peritoneal and the rest pleural) and 29 from lung cancers (lung or bronchus) were recorded. Other major sites for cancers were gastrointestinal (18 cases) and 21 of the genitourinary system. The remaining 21 cancers occurred in primary sites such as lymphatic and haematopoietic tissue; lip, mouth, and pharynx; larynx (two men); skin; brain; and six cases had an unspecified primary site.

The mean and range of ages of the subjects who died of mesothelioma or lung cancer were very similar: 59.8 (range 43-74) years and 60.5 (range 40-72) years, respectively. The male to female ratios for mesothelioma and lung cancers were 2.5 and 3 respectively.

Table 2 shows the cancer rates at age $\geqslant 30$, for the years 1975-94.

The rate for all cancers for men was 1557 per $10^{6}$, compared with 689 for women; a 2.3 times lower rate.
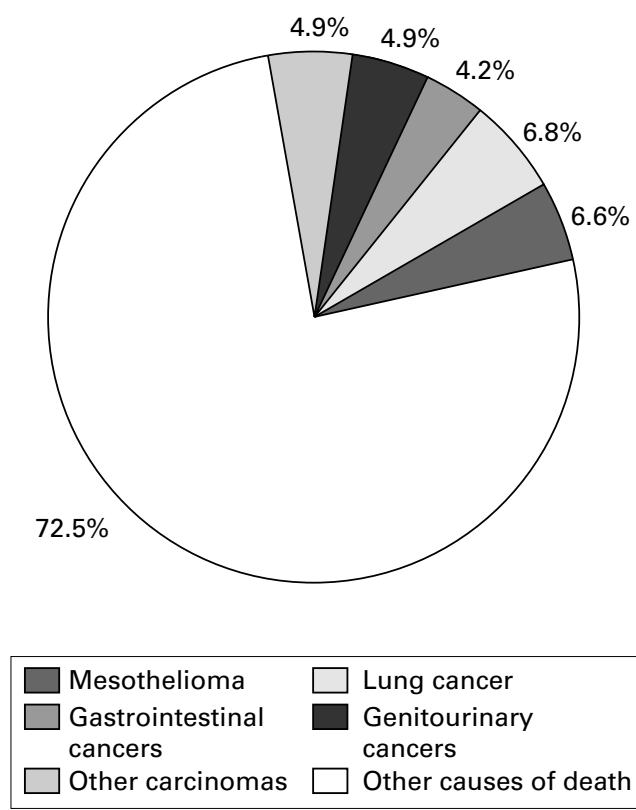

Figure 2 Proportion of cancer deaths in 415 deceased cohort members of $\geqslant 30$ years.
Table 2 Mortalities for all cancers, mesothelioma, and lung cancer for subjects $\geqslant 30$ (1975-95)

\begin{tabular}{llll}
\hline Cancer type & Men & Women & Total \\
\hline Person-years & 54598.5 & 46472.2 & 101071 \\
All cancers: & & & \\
Cases (n) & 85 & 32 & 117 \\
$\quad$ Rate & 1557 & 689 & 1158 \\
$95 \%$ CI & 1223 to 1891 & 449 to 929 & 952 to 1364 \\
Mesothelioma: & & & \\
$\quad$ Cases (n) & 20 & 8 & 28 \\
Rate & 366 & 48 to 296 & 277 \\
$95 \%$ CI & 202 to 530 & & \\
Lung cancer: & & 7 & 29 \\
Cases (n) & 22 & 151 & 287 \\
Rate & 403 & 27 to 274 & 135 to 436 \\
$95 \%$ CI & 239 to 567 & & \\
\hline
\end{tabular}

$\star$ Rates are in $10^{6}$ person-years.

The mortality for mesothelioma was 277 per $10^{6}$ person-years (95\% CI 170 to 384 ), but the rate for men was twice that for women: 366 and 172 per $10^{6}$ person-years, respectively. Again, most deaths due to lung cancers (lung and bronchus) were in men ( $76 \%$ ), with the rate for men almost three times that for women, and was very similar to those for mesothelioma.

Proportional cancer mortality ratios are shown in table 3.

The PCMRs for mesothelioma were significantly increased for all cases at 31.11 (95\% CI 20.7 to 43.6 ) and for men and women at 18.2 (95\% CI 11.1 to 27.7 ), and 26.7 (11.5 to 52.5), respectively. Although the PCMRs for lung cancers were also increased, these increases were not significant. The two cases of laryngeal cancer, both in men, produced a ratio 1.8 for all subjects and 1.7 for men. Cancer of the colon produced PCMRs $<1$. Seventeen cohort members, 15 men and two women, died of cancers of the digestive system, with PCMRs of $0.5,0.7$, and 0.4 for all subjects, men, and women respectively. The deficit of cases was significant for all digestive cancers $(0.5,95 \%$ CI 0.3 to 0.8$)$ but not for all colon cancers $(0.5$, 95\% CI 0.1 to 1.4 ). The PCMRs were not calculated for the remaining 41 cases of cancer as these cancers were thought not to be associated with exposure to asbestos.

Table 3 Proportional cancer mortality ratio (PCMR) analysis for all cancers, mesothelioma, lung, laryngeal, and colon cancers by sex, in subjects $\geqslant 30$ years who died between 1975-95

\begin{tabular}{|c|c|c|c|c|}
\hline & \multirow{2}{*}{$\begin{array}{l}\text { Observed } \\
n\end{array}$} & \multirow{2}{*}{$\begin{array}{l}\text { Expected } \\
n\end{array}$} & \multicolumn{2}{|c|}{ PCMR } \\
\hline & & & Rate & $95 \% C I$ \\
\hline \multicolumn{5}{|l|}{ All cancers: } \\
\hline Men & 86 & 59.6 & 1.4 & 1.1 to 1.8 \\
\hline Women & 32 & 20.5 & 1.6 & 1.1 to 2.2 \\
\hline Total & 117 & 79.8 & 1.5 & 1.2 to 1.7 \\
\hline \multicolumn{5}{|c|}{ Mesothelioma: } \\
\hline Men & 20 & 1.1 & 18.2 & 11.1 to 27.7 \\
\hline Women & 8 & 0.3 & 26.7 & 11.5 to 52.5 \\
\hline Total & 28 & 0.9 & 31.1 & 20.7 to 43.6 \\
\hline \multicolumn{5}{|l|}{ Lung: } \\
\hline Men & 22 & 20.5 & 1.1 & 0.7 to 1.6 \\
\hline Women & 7 & 4.8 & 1.5 & 0.6 to 3.0 \\
\hline Total & 29 & 23.3 & 1.2 & 0.8 to 1.8 \\
\hline \multicolumn{5}{|l|}{ Larynx: } \\
\hline Men & 2 & 1.2 & 1.7 & 0.2 to 6.0 \\
\hline Women & - & 0.1 & - & - \\
\hline Total & 2 & 1.1 & 1.8 & 0.2 to 6.5 \\
\hline \multicolumn{5}{|l|}{ Colon: } \\
\hline Men & 3 & 3.5 & 0.9 & 0.2 to 2.5 \\
\hline Women & 1 & 2.9 & 0.3 & 0.01 to 1.9 \\
\hline Total & 4 & 7.3 & 0.5 & 0.1 to 1.4 \\
\hline
\end{tabular}




\section{Discussion}

This study shows that mortalities due to mesothelioma in the Prieska area are very high at 277 per $10^{6}$ person-years overall and 366 and 172 per $10^{6}$ for men and women respectively. Partly as a consequence, the overall proportion of deaths due to cancer for cohort members $\geqslant 30$ years was high at $28.2 \%(117 / 415)$. The proportion of all lung cancer deaths was moderately increased in the cohort relative to the general population.

The PCMR analysis showed a deficit of cancer of the gastrointestinal tract. This could be explained by a see-saw effect with raised ratios of one cancer (mesothelioma) resulting in lowered ratios for others.

In the white population of South Africa, the latest available reported rate for histologically diagnosed mesothelioma is 37.0 and 16.3 per million in men and women respectively. ${ }^{14}$ Zwi et $a l^{15}$ calculated the standardised annual incidence of mesothelioma among white people $>15$ years to be 32.9 per $10^{6}$ for men and 9.9 per $10^{6}$ for women. The highest national rates reported elsewhere in the world were in the United States, ${ }^{16}$ and are much less then South Africa at 12.4 and 2.4 per $10^{6}$ for men and women respectively. By comparison, the rates in Prieska are 348 and $172\left(10^{6}\right.$ person-years) for men and women respectively, roughly 10 times the magnitude of the national incidence $^{15}$ and National Cancer Registry. ${ }^{14}$ The Prieska rates are similar to those found in Wittenoom for past residents of the crocidolite mining town who did not have occupational exposure to asbestos-namely, 267 per $10^{6}$ person-years. ${ }^{12}$

For white South Africans the reported crude mortality for lung cancer in men is 199 per million and for women 92.5 per million. In this birth cohort the mortality for carcinomas of the lung and bronchus was 287 per $10^{6}$ personyears, very similar to that for mesothelioma, 277 per $10^{6}$. As asbestos is associated with the development of both mesothelioma and lung cancers, these high rates indicate the severity of the consequences of past crocidolite exposure.

There are two main limitations in this study: the cohort was restricted to white subjects; and the extent of ascertainment of cases of disease related to asbestos is uncertain in both the study subjects and reference population. Underascertainment is possible as the diagnosis of a specific cancer may not have been made and thus not recorded as the cause of death. On the other hand, overascertainment of mesothelioma in the study population is possible if the doctors were influenced to diagnose mesothelioma because of a history of exposure to crocidolite.

It is unfortunate that the historical system of archiving deaths in the Department of Home Affairs restricted our mortality analyses to white subjects, because the different population groups probably had different profiles of exposure to asbestos. According to reports of the government mining engineer (the statutory authority), during the 1940 s and 1950 s most asbestos miners, cobbers, and mill workers in the crocidolite fields were coloured, and mortalities in this population group would incorporate the risk from occupational exposure. However, a predominance of coloured workers may not have pertained to Prieska. Botha et $a l^{6}$ reported on the racial breakdown of employees of the asbestos industry for the period 1929-60 in certain districts such as Kuruman, Prieska, and Hay, but the source of these data is not clear. It seems that in Prieska more white than coloured men were employed $(4 \% v 2.1 \%)$. By comparison, $2.2 \%$ of coloured women worked in the industry and only $0.2 \%$ of white women. The low rate of occupational exposure in white women is borne out by a recently conducted interview with a woman who worked as an asbestos mill manager in Prieska (Snyder J, personal communication, Prieska, 1999) and by archived data acquired on employment figures of the Prieska mill and mines in the Prieska Magisterial District ${ }^{17}$ : only one woman worker was identified and she was not born in Prieska, and thus was not part of the cohort. This scarcity of white women among asbestos workers is important to this study as white women were likely to have had purely environmental exposure. We suspect, therefore, that rates of mesothelioma for white women are as a consequence of purely environmental exposure to crocidolite. The rates in men are more likely to incorporate both occupational and environmental influences, but we do not yet know what proportion of men in the cohort died from work with asbestos as a survey of study members and their relatives is still under way.

Of the cohort of $2390,74 \%$ had been traced up to 31 December 1995; a similar rate $(71.4 \%)$ was reported in the Whitenoom study. ${ }^{12}$ The vital status was thus unknown for 614 of our subjects, but this may improve as deaths increase in this aging cohort resulting in more death certificates being obtained.

Some misclassification due to incorrect cause of death recorded on death certificates is likely. For example, some of the gastrointestinal cancers may have been peritoneal mesotheliomas, or some of the pleural mesotheliomas could have been adenocarcinomas of the lung. The size of this bias, should it exist, cannot be estimated. However, accuracy of cause of death as recorded on the death certificates was compared with necropsy findings and found to be fairly accurate for cancers in a South African community of miners and former miners. ${ }^{18}$ For example, death certificate diagnosis of lung cancer and mesothelioma had a positive predictive value of 83.3 (68.6-93.0).

All the deaths of children $<15$ years of age (213) were identified by manually searching the death registers for the Prieska district. This increased the follow up rate by $9 \%$. We recommend that researchers undertaking cohort studies of mortality in South Africa, especially those in young children or birth cohorts, make use of this method of identifying cases that might otherwise be lost to follow up.

\section{Conclusion}

The mortalities for mesothelioma were very high: 366 and 172 per million person-years. 
The higher rates in men are probably accounted for by occupational exposure to asbestos experienced by some of them. Nevertheless, the mortality in women was still high and probably a consequence of environmental exposure. Due to the long latent period of the development of this neoplasm, and continuing high production of crocidolite asbestos until the late $1970 \mathrm{~s}^{19}$ the cause specific mortality in this cohort can be expectd to increase rapidly over the next 10 years.

1 Hall AL. Memoir on the asbestos deposits in the Union of South Africa, 2nd ed. Pretoria, South Africa: Geological Survey Office, 1930

2 Sleggs CA, Marchant P, Wagner JC. Diffuse pleural mesothelioma in South Africa. S Afr Med F 1961;35:28-34.

3 Marchant P. The discovery of mesothelioma in the Northwestern Cape Province in the Republic of South Africa. Am F Ind Med. 1991;19:241-6.

4 Rees D, Myers JE, Goodman K, et al. Case-control study of mesothelioma in South Africa. Am F Ind Med. 1999;35 213-22.

5 Reid G, Kielkowski D, Steyn SD, et al. Mortality of an asbestos-exposed birth cohort: a pilot study. S Afr Med $\mathcal{F}$ 1990;78:584-6.

6 Botha J, Irwig L M, Strebel PM. Excess mortality from stomach, lung cancer and asbestosis and/or mesothelioma in crocidolite mining districts in South Africa. Am f Epidemiol 1986;123:30-40.

7 Sluis-Cremer GK, Liddell FDK, Bezuidenhout BZ. The mortality of amphibole miners in South Africa 1946-80. B f Ind Med 1992;49:566-75.
8 Vianna NJ, Polan AK. Non-occupational exposure to asbestos in malignant mesothelioma in females. Lancet 1978; i: 1061-7.

9 Dodoli D, Del Nevo M, Fiumalbi C, et al. Environmental household exposure and occurrence of pleural mesothelioma. Am f Ind Med 1992;21:681-7.

10 Magnani C, Ivaldi C, Botta M, et al. Pleural malignant mesothelioma and environmental asbestos exposure in Casale Monferrato, Piedmont. Preliminary analysis of a casecontrol study . Med Lav 1997;88:302-9.

11 Berry M. Mesothelioma incidence and community asbestos exposure. Environ Res 1997;75:34-40.

12 Hansen J, de Klerk NH, Musk AW, et al. Environmental exposure to crocidolite and mesothelioma. Am $\mathcal{F}$ Respir Crit Care Med 1998;157:69-75.

13 Central Statistical Service. Deaths whites, coloured and asians, 1990. Pretoria, South Africa: Government Printer, 1990. (Report No 03-09-01.)

14 National Cancer Registry. Incidence of histologically diagnosed cancer in South Africa, 1992. Johannesburg, South Africa: South African Institute for Medical Research, 1997.

15 Zwi AB, Reid G, Landau SP, et al. Mesothelioma in South Africa, 1976-84: incidence and case characteristics. Int $\mathcal{F}$ Epidemiol. 1989;18:320-9.

16 Spirtas R, Beebe G W, Connelly R R, et al. Recent trends in mesothelioma incidence in the United States. Am f Ind Med. 1986;9:397-407.

17 Archival records for Cape Blue Asbestos. Grikqua Town, South Africa: Mary Moffat Museum.

18 Kielkowski D. The determination of the underlying cause of death from death certificates: a study of South African practice [PhD Thesis]. Johannesburg, South Africa: University of the Witwatersrand, 1996.

19 Harrington JS, McGlashan ND. South African asbestos: production, exports and destinations, 1959-1993. Am f Ind Med 1998;33:321-6.

\section{Rejected manuscripts}

Authors whose submitted articles are rejected will be advised of the decision and one copy of the article, together with any reviewer's comments, will be returned to them. The
Fournal will destroy remaining copies of the article but correspondence and reviewers' comments will be kept. 